\title{
MOVILIDAD URBANA SOSTENIBLE EN CIUDADES INTERMEDIAS COLOMBIANAS Metodología y diagnóstico territorial
}

\author{
Autor: Milton Mauricio Moreno Miranda / Segundo autor: Juan Pablo Beltrán Cárdenas y Nicolás Esteban \\ Palomino Rozo. \\ Universidad Autónoma de Barcelona, Universidad Piloto de Colombia \\ Directores: Àngel Cebollada y Pau Avellaneda \\ mauriciomoreno100@gmail.com / milton-moreno@unipiloto.edu.co
}

\section{RESUMEN}

Este estudio presenta el resultado de la implementación de una metodología, la cual se utilizó en campo para levantar información relacionada con las condiciones de movilidad no motorizada de la ciudad de Zipaquirá. Para ello se utilizó la escala a nivel de "manzana", se trabajó con 83 polígonos y 347 bordes dentro del casco urbano.

Con base en el marco teórico, el cual se apoya en autores y referentes, se produce como resultado un diagnóstico territorial. Para ello se tuvo en cuenta el resultado obtenido en campo y el análisis de los instrumentos de planeación vigentes en la ciudad. Esto permitió evidenciar vacíos conceptuales presentes en tales documentos.

Finalmente, el artículo expone algunas conclusiones y recomendaciones que aportan a la reflexión en cuanto a las condiciones de movilidad de las ciudades intermedias en Colombia

Palabras clave: Movilidad, ciudad, sostenibilidad, urbanismo.

\begin{abstract}
In this paper we present the result of the implementation of a methodology, which was used to collect field information related to the conditions of non-motorized mobility of the city of Zipaquirá. We used urban block as work scale: 83 polygons and 347 edges within the urban center.

Based on the theoretical framework, which relies on authors and referents, a territorial diagnostic was generated. We analyzed the field results and the city planning instruments that currently has the city. This allowed to show conceptual gaps present in such documents.

Finally, we present some conclusions and recommendations that contribute to the reflection on the mobility conditions about intermediate cities in Colombia.
\end{abstract}

Key Words: Mobility, city, sustainability, urbanistic. 


\section{LA CIUDAD INTERMEDIA EN COLOMBIA Y LOS INSTRUMENTOS DE PLANEACIÓN}

\subsection{Contexto del lugar}

Colombia cuenta con cerca de 60 ciudades que superan los 100.000 habitantes (Duarte, 2009), de las cuales aproximadamente el $60 \%$ no alcanzan a los 300.000 . En el caso específico del departamento de Cundinamarca, tan sólo los siguientes 5 de los 116 municipios se encuentran en este rango poblacional, lo que ha hecho de estas urbes, unos territorios que cobran valor y relevancia a nivel regional.

Varias de estas ciudades presentan características similares, como lo son las tasas de crecimiento poblacional relativamente altas (2.2\% anual en Zipaquirá), la cantidad y calidad de algunos servicios especializados, el aumento del parque automotor, la cantidad de viajes que se realizan desde y hacia éstas, entre otras.

Todo lo anterior, sumado a la proximidad de algunas de las mencionadas ciudades a las grandes capitales, hacen que estos territorios cuenten con mayor visibilidad en la escala regional y que debido a su rápido crecimiento, logren tener intervenciones adecuadas a las necesidades de la mayoría de la población.

En el caso de Zipaquirá, ubicada a 40 kilómetros de la capital del país (ver figura 1), presenta varias de las características mencionadas de las denominadas ciudades intermedias; con una población de cerca de 120.000 habitantes (DANE, 2005), se posiciona en el departamento como una de las ciudades más importantes; tiene una prestación importante de servicios de educación y especialmente su vocación y actividad económica se basa en el turismo generado por la catedral de sal $^{1}$.

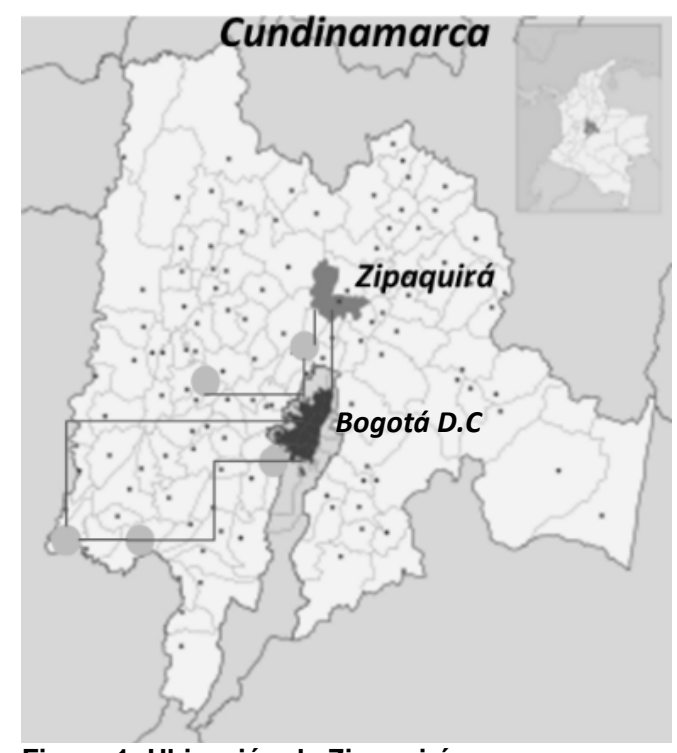

Figura 1: Ubicación de Zipaquirá

(Complementado de Wikipedia, 2015)

Parte del proceso de investigación, consistió en revisar tres escalas territoriales, con el fin de identificar las principales características y por consiguiente las falencias en materia de movilidad sostenible.

La escala regional fue la primera en abordarse, encontrando en ella que debido a las distancias entre municipios, la mayoría de los desplazamientos poblacionales se realizan en modos motorizados tanto públicos como privados, evidenciando un flujo importante de vehículos automotores a su alrededor (ver figura 2), lo cual respalda la idea de la ubicación estratégica del municipio por su cercanía a Bogotá.

\footnotetext{
${ }^{1}$ Obra arquitectónica y de ingeniería considerada la primera maravilla de Colombia.
} 


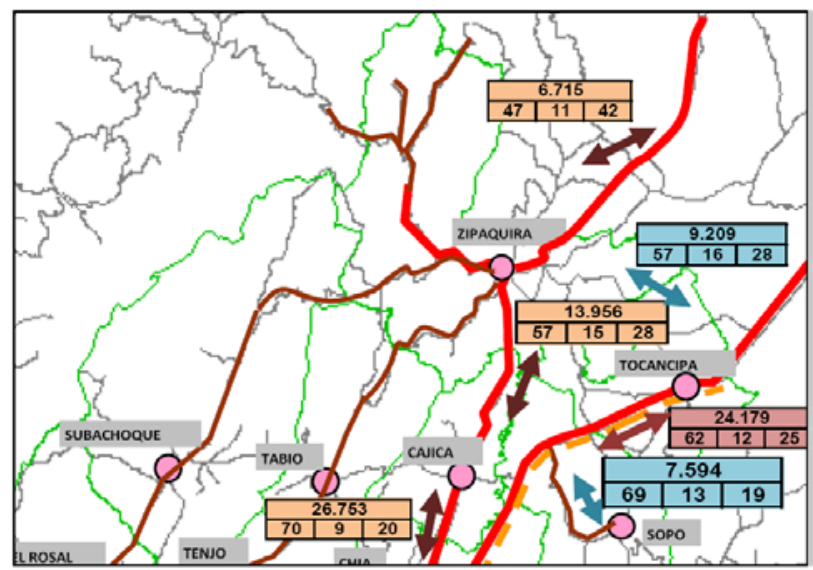

Figura 2: Tránsito promedio diario en la región - año 2007

(Universidad Nacional de Colombia, 2009)

La segunda escala analizada fue la municipal, donde se identificaban las características del modelo de ciudad tanto urbano como rural.

Se encontró que Zipaquirá era relativamente una ciudad concentrada donde pese a tener algunos asentamientos periféricos, la mayor parte de la población (cerca del $90 \%$ ) reside en el área urbana (DANE, 2005) ver Figura 3.

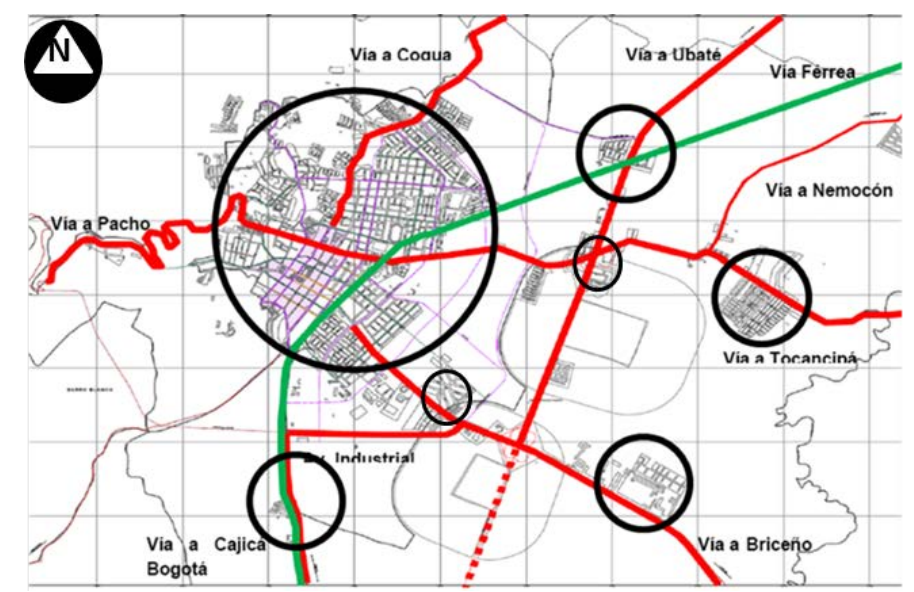

Figura 3: Asentamientos Urbanos en Zipaquirá

(Complementado de Universidad Nacional de Colombia, 2009)

Finalmente se abordó la escala barrial (ver figura 4), en la cual las condiciones de movilidad no son las más adecuadas, en especial por la falta de infraestructura para los modos de transporte no motorizados y la prevalencia para los automotores. La selección del casco urbano del municipio de Zipaquirá, se hace teniendo en cuenta factores como la importancia de los centros históricos, las cortas distancias para recorrerlos, el hecho de que la mayoría de los viajes inician y terminan donde reside la población, es decir donde se asienta la vivienda.

Allí se seleccionó un polígono que contiene cerca de 83 manzanas sobre las cuales se hace el presente estudio. El área es seleccionada partiendo del centro histórico de la ciudad y considerando a éste como la zona más importante con que cuentan las ciudades en general; para el caso de las ciudades intermedias colombianas, el centro compila la mayoría de los servicios, presenta una ubicación estratégica, mantiene la historia, cultura y arraigo de los pobladores, y es un claro ejemplo de la inadecuada distribución físico - espacial del territorio, ya que la mayor parte de su espacio público se destina a las infraestructuras viales, diferente a lo que sucede con el los andenes, plazas y parques. 


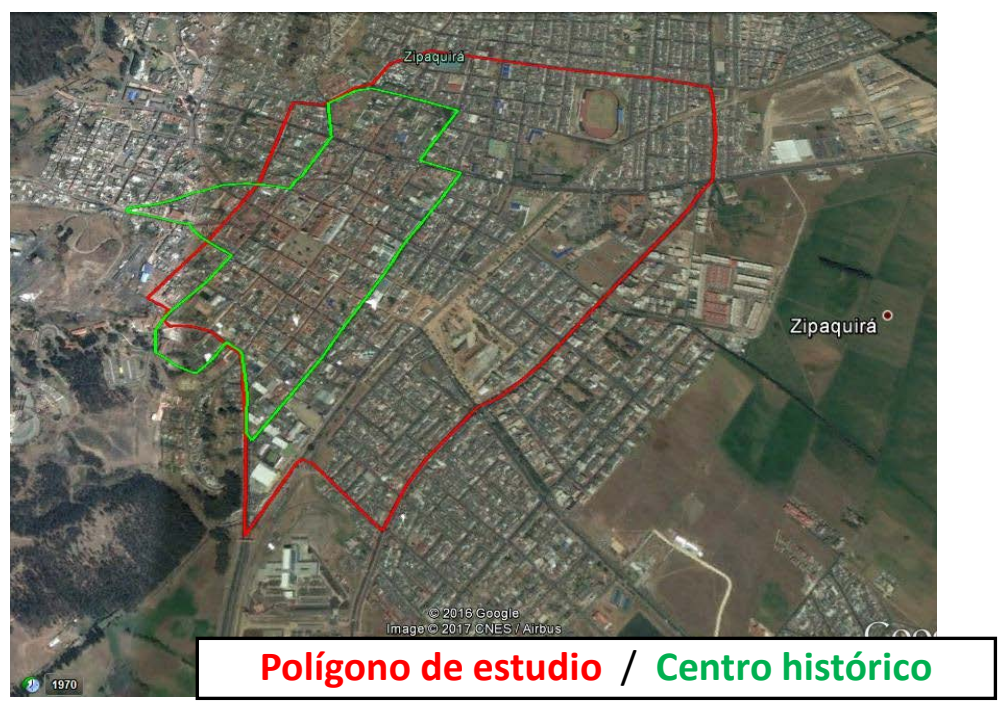

Figura 4: Casco urbano de Zipaquirá. Escala barrial (Complementado de Google Earth, 2016)

El sector escogido se delimitó además por vías principales que hacen parte de la estructura funcional de la ciudad, estas son de dimensiones importantes, dividen barrios y cuentan con presencia de transporte público; es considerada esta zona en Zipaquirá, como una mixtura importante de usos dotacionales como son colegios, equipamientos deportivos y culturales.

Sobre esta última escala de análisis, es que se detallará más adelante la metodología propuesta y el diagnóstico territorial que se obtuvo, adicionalmente se presenta una manzana como caso puntual, sobre la cual se realizan aforos de tráfico lo cual ejemplifica la manera como está planteado el modelo de movilidad de la ciudad.

Por otro lado, el estudio identificó también que la movilidad puede convertirse en una manera de planear territorios, y que las ciudades intermedias eran bastante adecuadas para ser tomadas como caso. La relación que tiene el tema de movilidad con el ordenamiento territorial, evidencia la necesidad de generar modelos basados en nuevos conceptos que aporten a un sistema más sostenible.

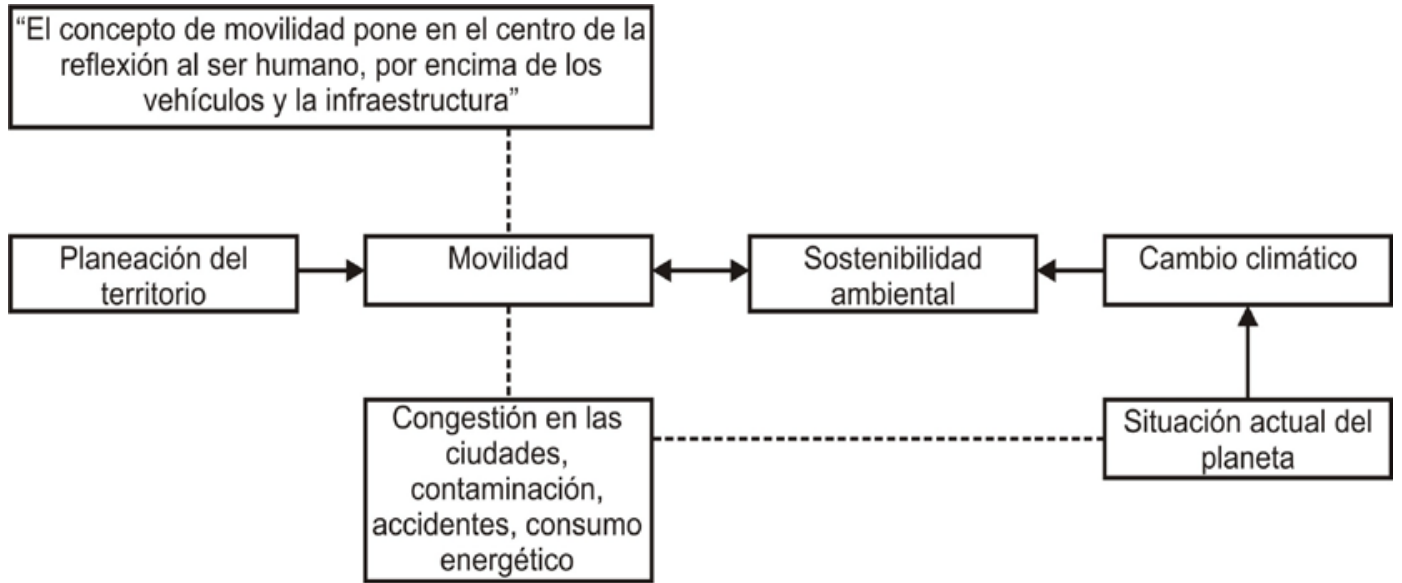

Figura 5. La Movilidad como elemento articulador de la planeación urbana y regional.

(Modificado de Montezuma, 2010)

Dentro de la revisión trabajada desde el marco teórico de la investigación, se indagaron históricamente algunos de los factores que influyeron en que hoy las ciudades y sus modelos de movilidad se comporten de la manera que lo hacen. Se encontró que el "periodo de la modernidad" había sido un momento decisorio en cuanto a que 
varias de las intervenciones urbanas de la época se dieron a partir de su desarrollo en las infraestructuras viales, y por tanto en los automotores (ver figura 6).

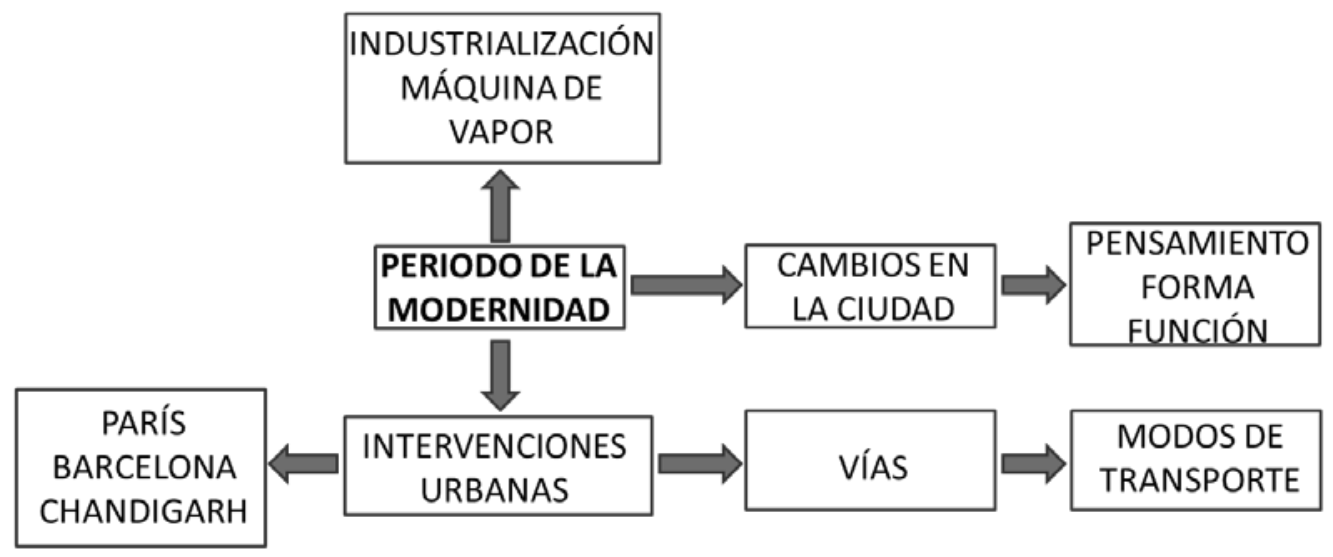

Figura 6. El periodo de la modernidad (Modificado de Benévolo, 1999)

La suma de todos estos elementos llevaron a definir el problema de la investigación como: "las ciudades intermedias en Colombia no cuentan con estrategias de intervención urbana, que basadas en un modelo de movilidad sostenible mejoren la calidad de vida de las personas", evidenciado esto en la manera como en el caso de estudio gran parte del espacio público se destina a las infraestructuras viales, dejando en un segundo plano al peatón y en general a los modos de transporte no motorizados.
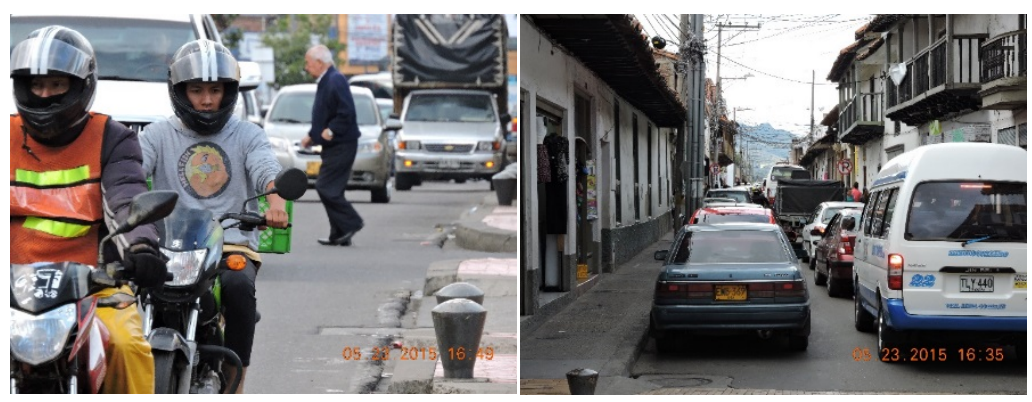

Imagen 1. Fotografías de Zipaquirá (Archivos del autor, 2015)

Con la revisión de varios referentes tanto nacionales como internacionales, también se logra demostrar que en la medida en que se le otorgue espacio en la ciudad a los modos de transporte no motorizados, las personas se apropian de los lugares y estos se convierten en sitios de concurrencia.

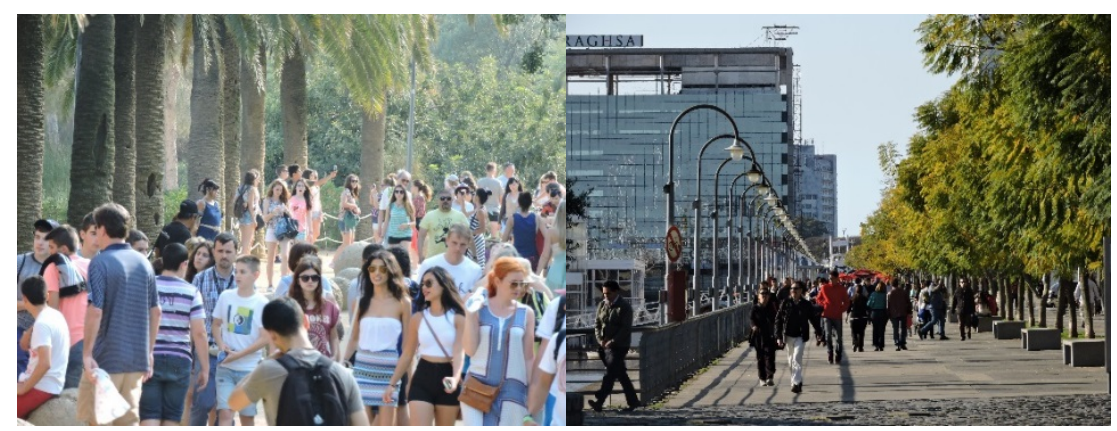

Imagen 2. Fotografías de Barcelona y Buenos Aires

(Archivos del autor, 2015) 


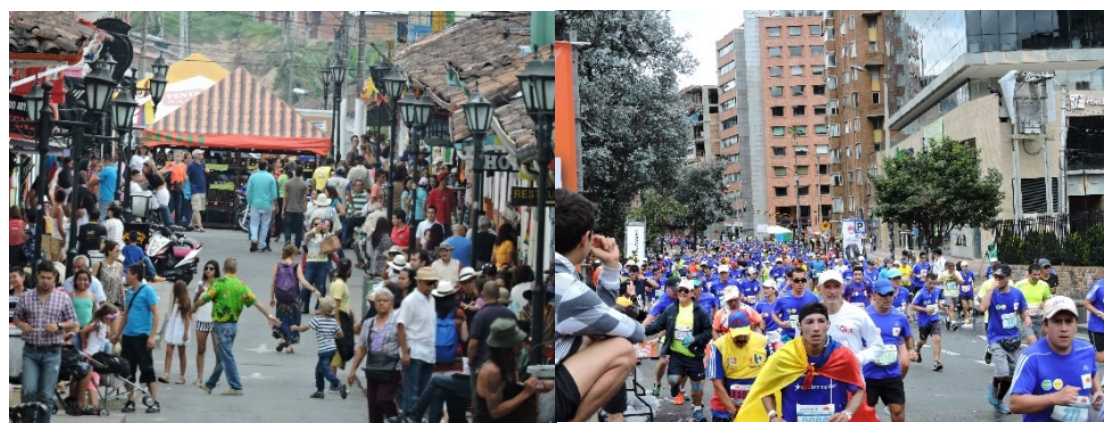

Imagen 3. Fotografías de Bogotá y Salento

(Archivos del autor, 2015)

Al igual que en muchas ciudades del mundo, el uso de la motocicleta se incrementa de manera alarmante, las aparentes ventajas que tiene han hecho de estas, un vehículo con gran presencia en la ciudad intermedia en Colombia. Las externalidades negativas que se derivan del uso de la motocicleta son bastantes, temas como la invasión del espacio público, la contaminación ambiental, los altos índices de accidentalidad, siendo éste último uno de los aspectos más preocupantes; en Colombia en el año 2010, cerca de 17.000 personas sufrieron accidentes en moto, más del $10 \%$ perdieron la vida (ver figuras 7 y 8 ).

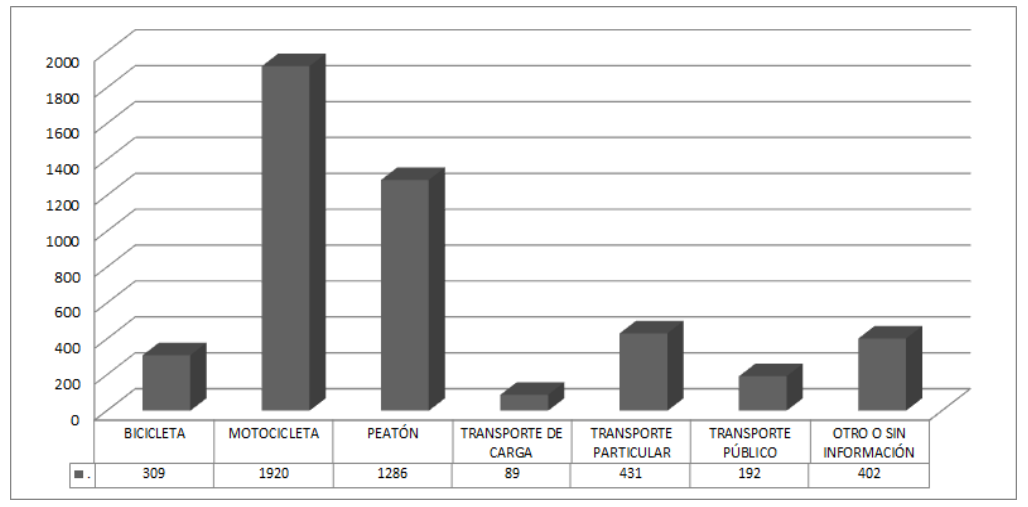

Figura 7. Estadísticas de la accidentalidad en Colombia año 2010. Número de muertos por modo de transporte (Modificado de Fondo de prevención vial, 2012)

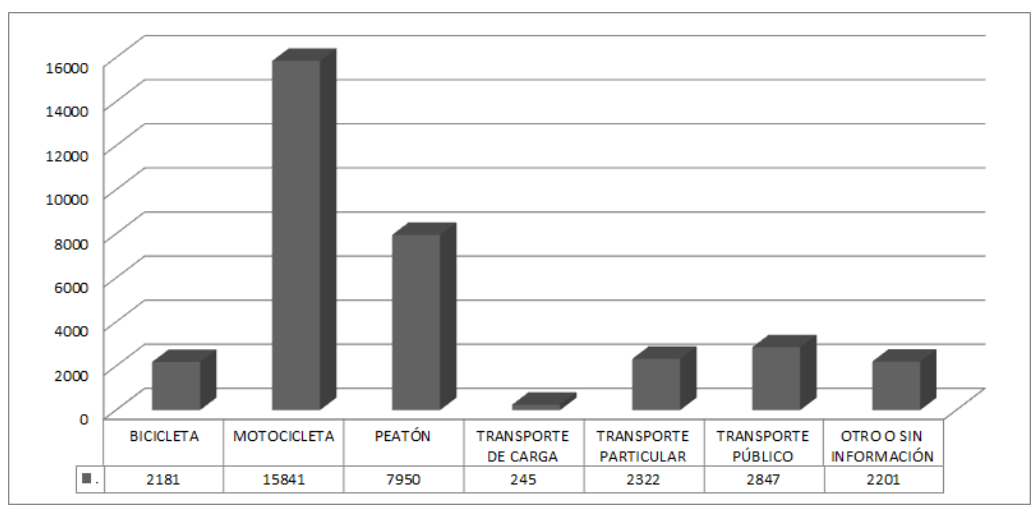

Figura 8. Número de heridos por modo de transporte (Modificado de Fondo de prevención vial, 2012)

Lo anterior demuestra la necesidad que tienen las ciudades de intervenir los modelos de movilidad planteados para de esta manera lograr mejorar los indicadores en cuanto a sostenibilidad ambiental, económica y social. 


\subsection{Análisis de los instrumentos de ordenamiento territorial en Zipaquirá}

El Plan de Ordenamiento Territorial de Zipaquirá, define sus políticas, objetivos y estrategias de intervención urbana a partir de cuatro grandes grupos como son: los usos del suelo, los equipamientos, el espacio público y la movilidad y el transporte, es por ello que se presenta el análisis por categorías, teniendo en cuenta este modelo, con el fin de que el POT pueda ser revisado desde su misma estructura.

\subsubsection{Usos del suelo}

Zipaquirá es un municipio donde predomina el uso de residencial, con vivienda unifamiliar y multifamiliar de baja altura (máximo 6 pisos), pero en los últimos años, ha presentado desarrollos importantes en cuanto a instituciones de servicio, en especial de educación, las cuales según el POT, ocupan cerca del 15\% del área total de la ciudad (ver tabla 1).

\begin{tabular}{|c|c|c|c|c|c|}
\hline 1. & \multicolumn{3}{|c|}{ USO DE VIVIENDA EN EL AREA URBANA DESARROLLADA } & $45 \%$ & $268.76 \mathrm{Ha}$ \\
\hline \multirow{4}{*}{2.} & \multirow{4}{*}{ 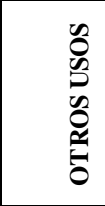 } & AREAS LIBRES Y ZONAS VERDES & $5 \%$ & \multirow{4}{*}{$55 \%$} & \multirow{4}{*}{ 328.49 Ha } \\
\hline & & VIAS & $25 \%$ & & \\
\hline & & EQUIPAMIENTOS Y USO INSTITUCIONAL & $15 \%$ & & \\
\hline & & INDUSTRIA COMERCIO Y USO MIXTO & $10 \%$ & & \\
\hline & \multicolumn{3}{|l|}{ TOTAL } & $100 \%$ & $597.25 \mathrm{Ha}$ \\
\hline
\end{tabular}

Tabla 1. Ocupación del suelo en el área urbana desarrollada

(Concejo Municipal de Zipaquirá, 2003)

Los usos del suelo son una prioridad en el ordenamiento de una ciudad, y la manera convencional como el tema es abordado por los instrumento de planeación no ha sido lo suficientemente detallada para mejorar las condiciones del territorio, la infraestructura vial presenta porcentajes altos que contravienen los modelos de movilidad sostenible para una ciudad intermedia, mientras que las zonas verdes y áreas libres se convierten en el restante de suelo.

La propuesta metodológica, busca en este punto abordar tres temas prioritarios para ser tenidos en cuenta en el desarrollo de las políticas de planeación de las ciudades intermedias:

a- El modelo de ciudad: Si se pretende tener un modelo de ciudad sostenible en materia de movilidad urbana, se procura una ciudad compacta, donde los desplazamientos de hacen lo más cortos posibles (Herce, 2009).

b- La distribución de los usos del suelo: La mezcla de algunos usos ayuda a tener un territorio consolidado en todos sus sectores y las distancias disminuyen.

c- Los porcentajes de cada uso: La infraestructura vial debe reducirse en los cascos urbanos y liberar áreas para otras funciones como zonas recreativas, culturales y de integración social.

\subsubsection{Equipamientos}

Las ciudades intermedias se consolidan como prestadoras de servicios, dependiendo su vocación, jerarquía a escala regional y población objetivo. En el caso de Zipaquirá, históricamente el turismo ha sido reconocido por la Catedral de Sal que pese a que sigue siendo de gran valor a nivel nacional, la demanda regional de educación ha posicionado la ciudad como núcleo de equipamientos para esta función. Las edificaciones prestadoras de este servicio, por su uso se definen de cierta manera como unas centralidades emergentes ya que la los flujos poblacionales que generan son importantes.

Los modelos de movilidad sostenible, presentan los equipamientos como elementos significativos dentro de la estructura urbana, ya que sus funciones son relevantes para la ciudad y generan dinámicas sociales y económicas. Por su jerarquía, los equipamientos merecen una respuesta especial en cuanto a movilidad, las cortas distancias entre estos servicios y la vivienda por ejemplo son de vital importancia, ya que a menor distancia, mayor seguridad para los transeúntes (UNC, 2011). 
En el caso de estudio, las instituciones educativas nuevas han surgido hacia la periferia, lo cual genera expansión de la ciudad, sectorización de la misma y recorridos más lejanos.

Es importante que los planes de movilidad definan en los instrumentos del ordenamiento, estrategias de intervención urbana que permitan dar cabida a los equipamientos de educación, salud, cultura, recreación, deporte, dentro de los cascos urbanos, sin que estos generen impactos negativos en su contexto.

\subsubsection{Espacio Público}

Se entiende como espacio público, todas aquellas zonas de uso colectivo de la sociedad; precisamente uno de los inconvenientes al abordar el tema es limitar el uso de algunos espacios para una porción de población, como es caso de la calle, ya que el concepto de ésta como espacio público empieza a ser controversial en el momento en que se revisan las funciones que sobre ella se desarrollan, es decir, hoy la calle es únicamente para el desplazamiento en modo de transporte motorizado y si el peatón la camina por allí, automáticamente es más vulnerable a sufrir accidentes.

Las infraestructuras viales se definen según su perfil (dimensiones y número de carriles), pero el borde, las funciones y su ubicación, son otros factores que se tendrían que estudiar más al detalle en el momento de proponer intervenciones urbanas dentro de la ciudad. Un estudio en tres calles de San Francisco, Estados Unidos, demostró que las calles son elementos de encuentros sociales, y que entre menos tráfico motorizado circule por las mismas, mayores son las interacciones y viceversa (ver figura 9).
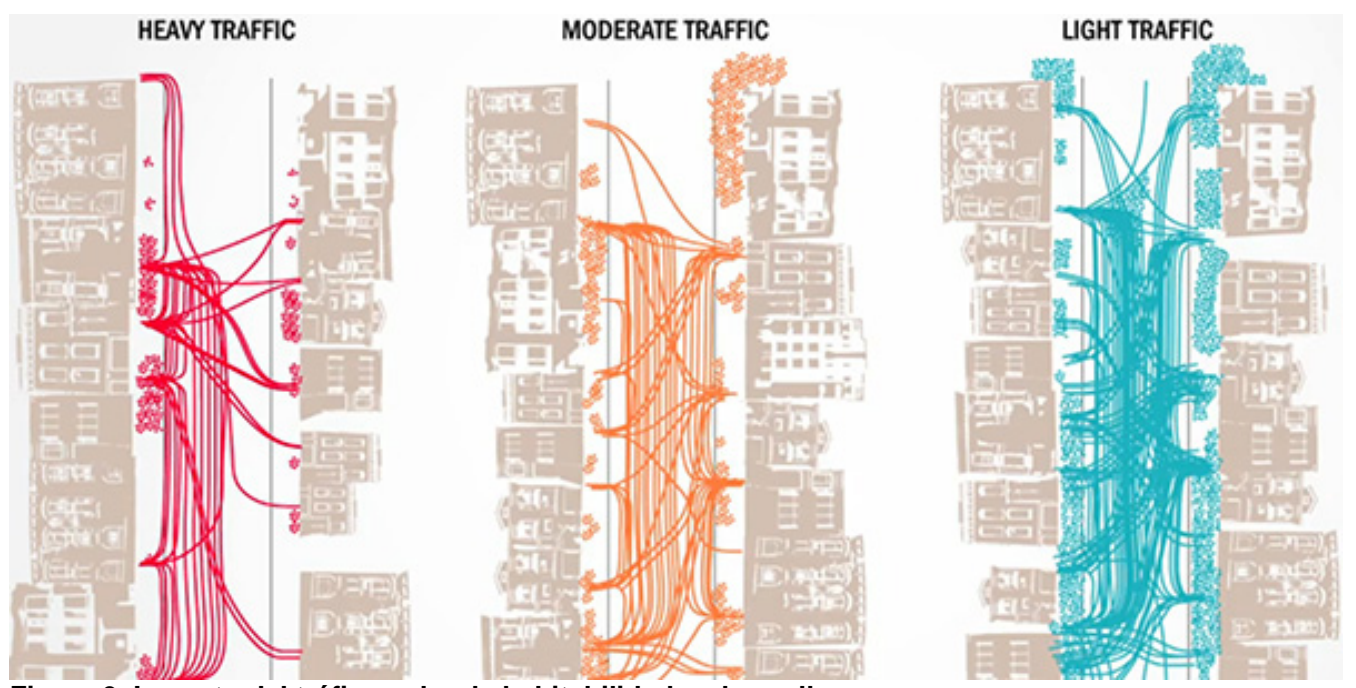

Figura 9. Impacto del tráfico sobre la habitabilidad en las calles (Appleyard, Gerson, Lintell, 1981)

Otro vacío que se encuentra en los instrumentos de ordenamiento territorial, es que siempre se hace mención a la cantidad del espacio público, mas no a la calidad del mismo, siendo éste el lugar donde se dan la mayor parte de las interacciones sociales del ser humano. Las plazas, son polos atractores de población, sitos destinados para eventos, para congregar masas de gente, por lo tanto el estado en que se encuentren, serán definitivos para su uso.

Al igual que sucede con los equipamientos, la ubicación estratégica de los espacios públicos dentro de la ciudad definirá el nivel de vitalidad que tengan dichas zonas.

\subsubsection{Movilidad y Transporte}

Los instrumentos de planeación en las ciudades intermedias han demostrado tener una visión errada del concepto de movilidad, por el hecho de que se asimila que es igual que el transporte (Moreno, 2013). 
En el periodo de la modernidad hacia 1800, las ciudades en Europa inicialmente presentaron cambios importantes en su forma y en su función, las urbes se concibieron como máquinas en constante movimiento cuyo objetivo principal era producir. Fue un siglo lleno de grandes planes urbanos tales como el de Haussmann en Paris, o el de Cerdá en Barcelona, o Ghandigarth (Benévolo, 1999). Todas estas intervenciones tuvieron algo en común, ordenaban el territorio a partir de la infraestructura vial; las ciudades en un par de años se vieron invadidas por grandes ejes viales, destinados obviamente para los motorizados.

El transporte se encargó desde ese momento de estudiar lo referente a las infraestructuras viales y los automotores en especial. El concepto de movilidad por el contrario es mucho más reciente, da una mirada integral sobre la manera como se desplazan las personas y las mercancías, teniendo en cuenta temas como el motivo del viaje, los horarios, el modo de transporte, y siempre asumiendo que el centro de todo es el peatón (Montezuma, 2009).

Confundir los conceptos es la base de los problemas que se identificaron en el POT de Zipaquirá, ya que bajo la intención de abordar la movilidad, se termina haciendo referencia únicamente a las vías y a los vehículos, es decir se implementan modelos de transporte únicamente.

Un primer punto que la investigación logró demostrar, fue la manera como se abordan las escalas territoriales de igual forma, pese a que las necesidades son distintas. Se encontró que la escala regional es la que conecta los diferentes municipios de una región, siendo este aspecto donde se centran la mayoría de intervenciones de transporte por parte de los gobiernos locales y en el balance general, se puede decir que las condiciones de conectividad por medio de las vías es buena.

La segunda escala es la municipal la cual se refiere a la conexión entre el suelo urbano y el rural; en el caso de las ciudades intermedias, donde la mayoría de la población se concentra en la zona urbana y los movimientos poblacionales son menores hacia esta periferia. De igual manera, existen unas condiciones relativamente favorables para dichos desplazamientos, que por lo general al igual que en la escala anterior se llevan a cabo en modos de transporte motorizados.

Finalmente el barrio se tomó como la tercera y menor escala de análisis, y fue allí, donde se encontró que las condiciones de movilidad para la mayoría de personas no son favorables. Son las áreas más descuidadas por las administraciones municipales pese a ser donde mayor cantidad de población se concentra, donde inician y terminan la mayoría de los recorridos, donde ocurren la mayoría de los accidentes y donde menos se hace necesario el uso del automóvil privado, como afirma Herce "es allí donde más se ha de restringir el uso del coche, donde menos espacio viario existe para la compatibilidad con otras funciones urbanas y donde menos necesario resulta el automóvil para soportar la demanda de la movilidad" (2009, p. 170).

\section{MARCO TEÓRICO}

La investigación busca evidenciar las diferencias conceptuales entre transporte y movilidad, para lo cual se revisan algunos autores que serán la base teórica que brinda el soporte para el análisis de los instrumentos de ordenamiento territorial dispuestos para Zipaquirá y posterior diagnóstico a partir de la metodología propuesta.

La comparación de los conceptos, presenta las ventajas de realizar los planteamientos urbanos con base en una teoría de movilidad y no de transporte, ya que esta última prioriza las infraestructuras viales y los automotores, lo cual hace que sea insostenible por los múltiples perjuicios que esto trae consigo para la ciudadanía en general (ver figura 10). 
RECIENTE

SER HUMANO

VISIÓN INTEGRAL

$\downarrow$

a DERECHO

- CAPACIDAD

- NECESIDAD

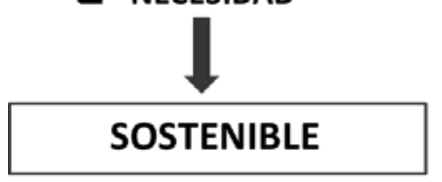

a MEDIO AMBIENTE

- SOCIEDAD

口 ECONOMÍA a ANTIGUO

INFRAESTRUCTURA VIAL

- VEHÍCULOS MOTORIZADOS

I

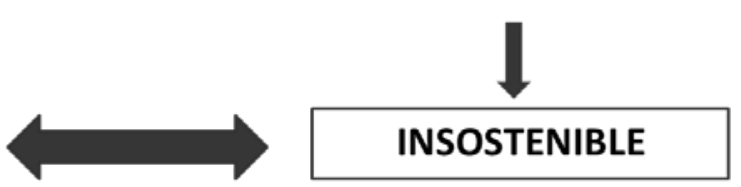

Figura 10: Aproximación teórica y conceptual.

(Elaborado por el autor, 2013)

El abordaje teórico de la investigación presenta también un estudio de referentes, en donde se busca por medio de intervenciones urbanas y políticas locales, incentivar el uso de los modos de transporte no motorizados como son la marcha a pie y la bicicleta.

En el caso de las ciudades Latinoamericanas, desde hace algunos años ha prestado mayor atención a la movilidad tanto de personas como de mercancías, para el primer caso, han surgido grandes proyectos como los metros o los $\mathrm{BRT}^{2}$ (Bus Rapid Transit); aparecen también algunas otras intervenciones de menor escala como las ciclo rutas, el carril bici, o programas como la ciclo vía en Bogotá, con el fin de promover el uso de la bicicleta y el modo peatonal.

Estas dos últimas formas de desplazamiento son sin duda la manera más adecuada de llevar a cabo los recorridos, en cuanto a sostenibilidad ambiental, social y económica dentro de la ciudad, lo cual (con pocos años más de experiencia) se ha demostrado en ciudades europeas que con el tiempo han venido consolidado más y más estos modos de transporte. Algunos de los mejores ejemplos son los programas vigentes en Paris, Copenhague y Barcelona (ver figuras 11, 12 y 13).

\footnotetext{
${ }^{2}$ Buses de tránsito rápido: sistema de transporte de buses con carriles exclusivos, presentan algunas ventajas sobre los metros como la flexibilidad, fácil adaptabilidad a la ciudad y bajos costos de construcción y mantenimiento.
} 


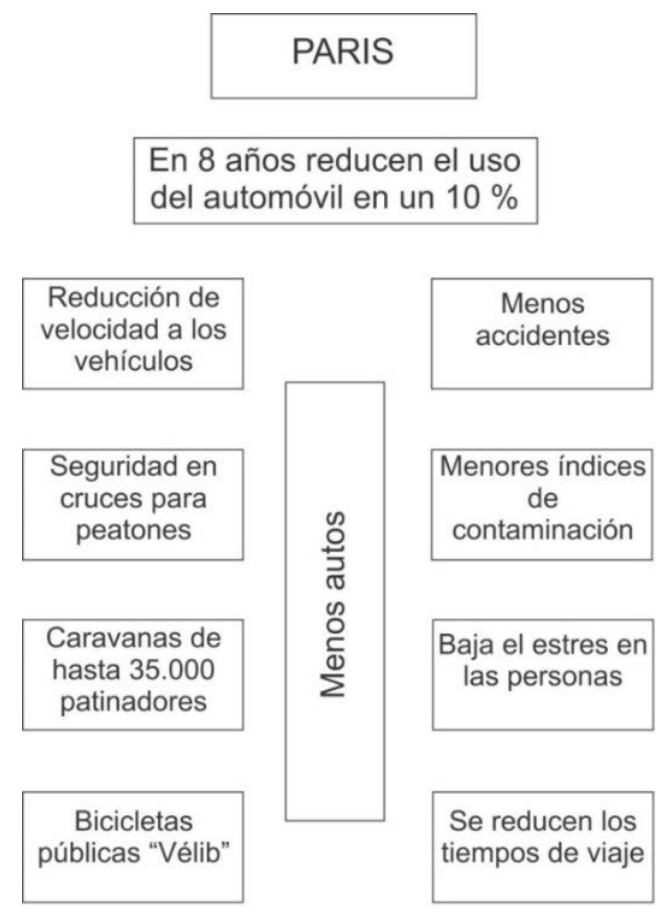

Figura 11. Programas de movilidad en París (Modificado de Montezuma, 2010)

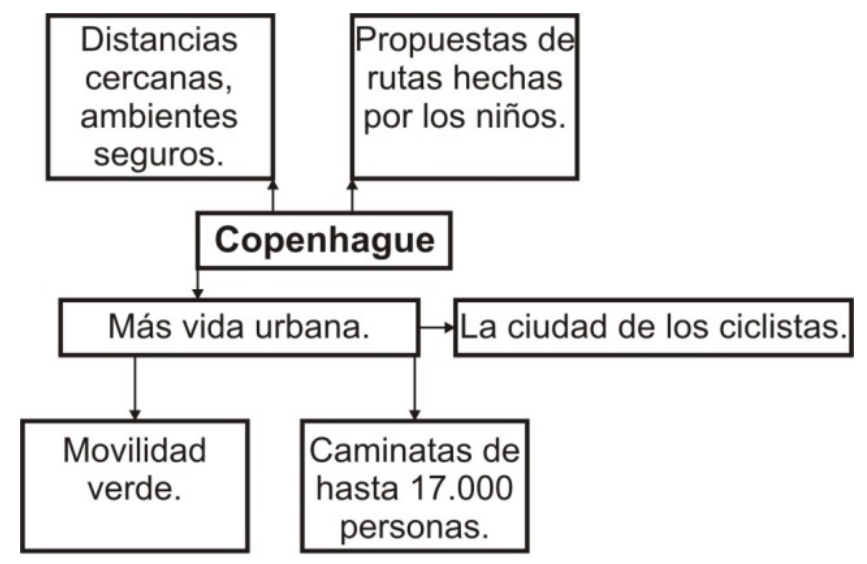

Figura 12. Estrategias de movilidad en Copenhague (Modificado de Cycling Embassy of Denmark, 2012)

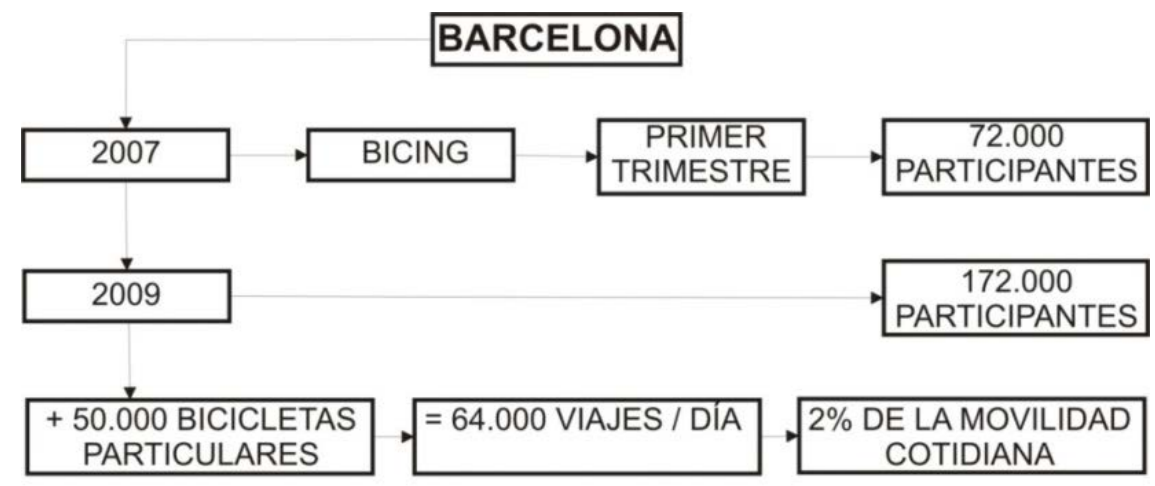

13\% DE INCREMENTO DE USUARIOS EN EL 2009

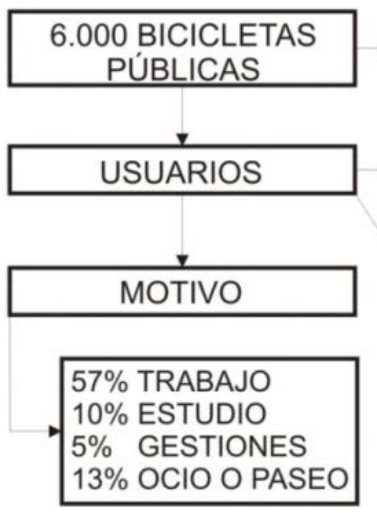
3.5 POR CADA 1.000
HABITANTES

$50 \%$ DE 20 - 35 AÑOS

$30 \%$ COMBINA CON OTRO MEDIO T.P.

Figura 13. Bicicletas públicas en Barcelona (Modificado de Herce, 2009) 
De esta forma, y luego de revisar algunas intervenciones urbanas y programas planteados en los anteriores referentes, se procede a plantear la metodología con la cual se podrá cuantificar y cualificar las infraestructuras que responden a los desplazamientos de los modos no motorizados, esto con base en el análisis de los instrumentos de planeación de Zipaquirá como fueron el $\mathrm{POT}^{3}$ y el $\mathrm{PM}^{4}$, y partiendo del respectivo soporte teórico.

\section{PROPUESTA METOdOLÓgICA}

Luego del diagnóstico que arrojó la revisión de los instrumentos de ordenamiento territorial, se definió una metodología para poder llegar a proponer intervenciones en el municipio. Un primer punto a tratar era los nuevos conceptos que debían ser tenidos en cuenta si realmente se buscaba un modelo de ciudad con mejores condiciones de movilidad. Por otro lado, se requería un método de levantamiento de información que pudiera ser utilizado en campo, que relacionara el marco teórico y que además pudiera basarse en datos estadísticos para medir las condiciones del territorio por medio de indicadores; es por ello que a continuación se presentan las tres matrices que se obtuvieron a partir de la investigación, y que constituyen un aporte parcial como respuesta a los objetivos trazados por el presente proyecto.

La metodología mixta busca medir componentes cualitativos y cuantitativos del territorio, es por ello que la "Matriz de escala urbana" (ver tabla 2), presenta estos dos enfoques, y tiene la capacidad de hacer una revisión general a través de categorías de análisis similares a las planteadas por los instrumentos de planeación, lo cual a su vez hace de esta un elemento que tiene la posibilidad de utilizarse en otra ciudad intermedia de características similares a las de Zipaquirá.

\footnotetext{
${ }^{3}$ Plan de Ordenamiento Territorial de Zipaquirá.

${ }^{4}$ Plan de Movilidad de Zipaquirá
} 


\begin{tabular}{|c|c|c|c|c|c|}
\hline & \multicolumn{3}{|c|}{ ENFOQUE CUANTITATIVO } & \multicolumn{2}{|c|}{ ENFOQUE CUALITATIVO } \\
\hline & \multicolumn{3}{|c|}{ Físico - Construido } & \multicolumn{2}{|c|}{ Actividades Humanas } \\
\hline & & Preguntas & Observación & Preguntas & Observación \\
\hline & & Qué existe & Inventario & Quién lo usa & Perfín de usuario \\
\hline & & En qué condiciones está & Estado & Cómo y porqué lo usa & Motivo \\
\hline & & Cuánto hay - de qué dimensiones & Mediciones & & \\
\hline CATEGORÍA & Tema & Item & Detalle & Item & Detalle \\
\hline \multirow{5}{*}{$\begin{array}{l}\text { Usos del } \\
\text { Suelo }\end{array}$} & \multirow{4}{*}{ Usos del Suelo } & Equipamientos (Dotacional) & $\begin{array}{l}\text { Valor histórico, hace cuanto existe, } \\
\text { población que acoge. }\end{array}$ & & \\
\hline & & Vivienda & $\begin{array}{l}\text { Tipologuía: Unifamiliar, bifamiliar, } \\
\text { multifamiliar, conjunto. Distancias a } \\
\text { los demás usos (mínima, media y } \\
\text { máxima) }\end{array}$ & & \\
\hline & & Comercio & Tipo: Escala barrial, zonal, municipal. & & \\
\hline & & Industria & & & \\
\hline & Densidades & Llenos y vacíos & Cruzando con usos y alturas & & \\
\hline \multirow{3}{*}{$\begin{array}{l}\text { Condiciones } \\
\text { Ambientales }\end{array}$} & \multirow{3}{*}{$\begin{array}{l}\text { Aspectos } \\
\text { ambientales }\end{array}$} & Presencia de arbolado & Tipo & & \\
\hline & & Condiciones climáticas & $\begin{array}{l}\text { Protección contra lluvia - sol } \\
\text { (voladizos, pérgolas). }\end{array}$ & & \\
\hline & & Topografía & Pendientes & & \\
\hline \multirow{8}{*}{$\begin{array}{l}\text { Espacio } \\
\text { Público }\end{array}$} & \multirow{2}{*}{ Espacio Público } & Plazas parques & Dimensiones & Presencia de Basuras & \\
\hline & & Vacíos Urbanos & Lotes y parqueaderos & & \\
\hline & Actividad & & & Perfíl del ususario & \\
\hline & $\begin{array}{l}\text { Obstáculos } \\
\text { físicos }\end{array}$ & $\begin{array}{l}\text { Apropiación indevida del espacio } \\
\text { público }\end{array}$ & Rejas en antejardín. & $\begin{array}{l}\text { Obstáculos momentáneos (parqueo } \\
\text { de vehículos en el espacio público) }\end{array}$ & \\
\hline & Mobiliario & Canecas, sillas, luminarias & & & \\
\hline & \multirow{2}{*}{ Tipologías } & Tipos de manzanas & Tamaños, permeabilidad. & & \\
\hline & & Alturas edificaciones & & & \\
\hline & Emplazamiento & Articulación edificio calle & & & \\
\hline \multirow{12}{*}{$\begin{array}{l}\text { Movilidad y } \\
\text { Transporte }\end{array}$} & \multirow{2}{*}{ Seguridad víal } & Señalización & Horizontal y vertical. & & \\
\hline & & Tipos de cruces & $\begin{array}{l}\text { Presencia de semaforos, cebras, } \\
\text { puentes peatonales. }\end{array}$ & $\begin{array}{l}\text { Utilización adecuada de la } \\
\text { infraestructura existente. }\end{array}$ & \\
\hline & \multirow{5}{*}{$\begin{array}{l}\text { Transporte } \\
\text { público }\end{array}$} & Individual (taxis) & Cantidad & Sectores de mayor afluencia. & \\
\hline & & Colectivo (buses y busetas) & & & \\
\hline & & Paraderos & & & \\
\hline & & Urbano, rural, intermunicipal. & & & \\
\hline & & Tiempos y distancias & Velocidad promedio & & \\
\hline & \begin{tabular}{|c|}
$\begin{array}{c}\text { Infraestructura } \\
\text { víal }\end{array}$ \\
\end{tabular} & Tipo: Tamaño vías & $\begin{array}{l}\text { Ancho en metros y número de } \\
\text { carriles. }\end{array}$ & Estado: Bueno, regular o malo. & \multirow{2}{*}{$\begin{array}{l}\text { Circulación de la población por los } \\
\text { andenes y vías. Uso adecuado } \\
\text { (número de personas que transitan } \\
\text { por la calle y el andén) }\end{array}$} \\
\hline & \begin{tabular}{|c|}
$\begin{array}{c}\text { Infraestructura } \\
\text { Peatonal }\end{array}$ \\
\end{tabular} & Tipo andén & Dimensiones: alto y ancho & Estado: Bueno, regular o malo. & \\
\hline & \multirow{2}{*}{ Flujos } & Modos de transporte & Volumen de tráfico & Motivo viaje, externalidades (+ -) & \\
\hline & & Día, hora y sentido & & Congestión, ruido. & \\
\hline & Normativa & Permiso de parquear en la calle & & $\begin{array}{l}\text { Percepción de la población respecto } \\
\text { de la normativa existente. }\end{array}$ & \\
\hline
\end{tabular}

Tabla 2. Matriz de escala urbana

Elaborado por el autor.

Con el propósito de tener mayor detalle de las condiciones urbanas del municipio estudiando, se definieron las matrices de escala manzana y escala predio (ver tablas 3 y 4), con las cuales se pretende hacer una medición más puntual del lugar, que permita de igual manera proponer estrategias de intervención sobre el territorio de la manera más acorde a las verdaderas necesidades de la población. 


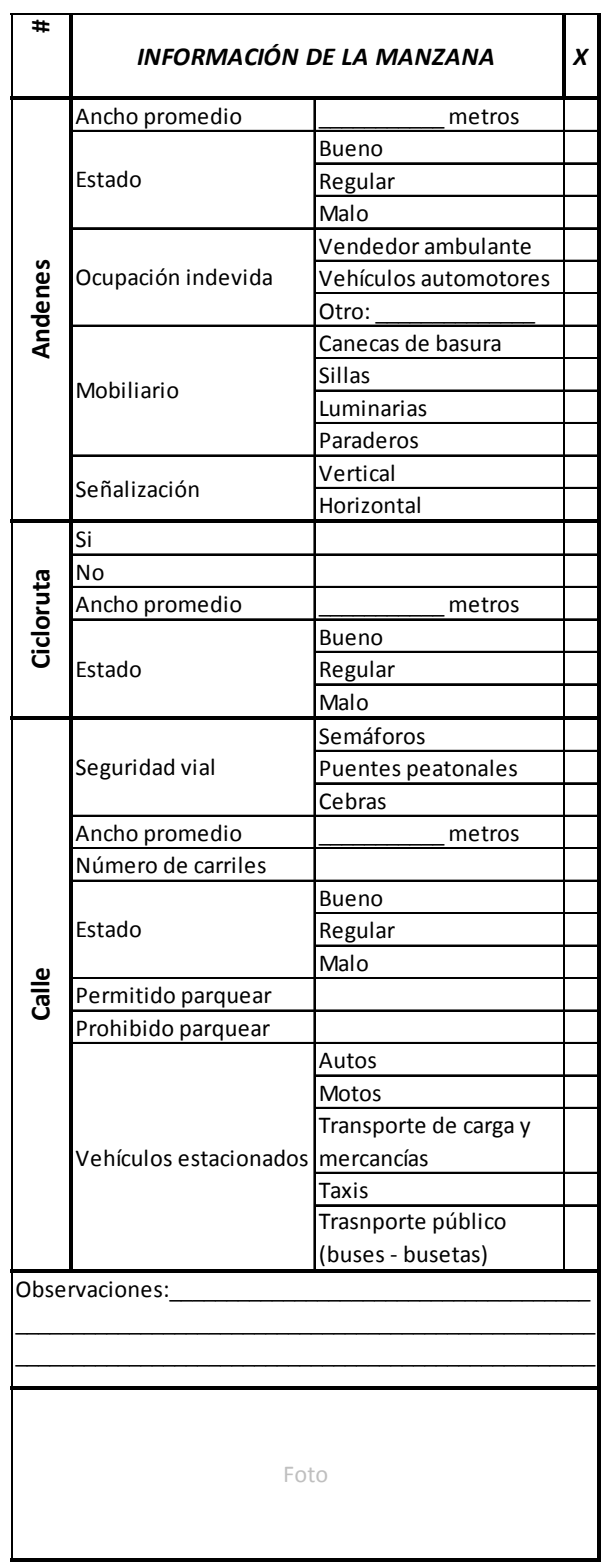

Tabla 3. Matriz de escala manzana

Elaborado por el autor

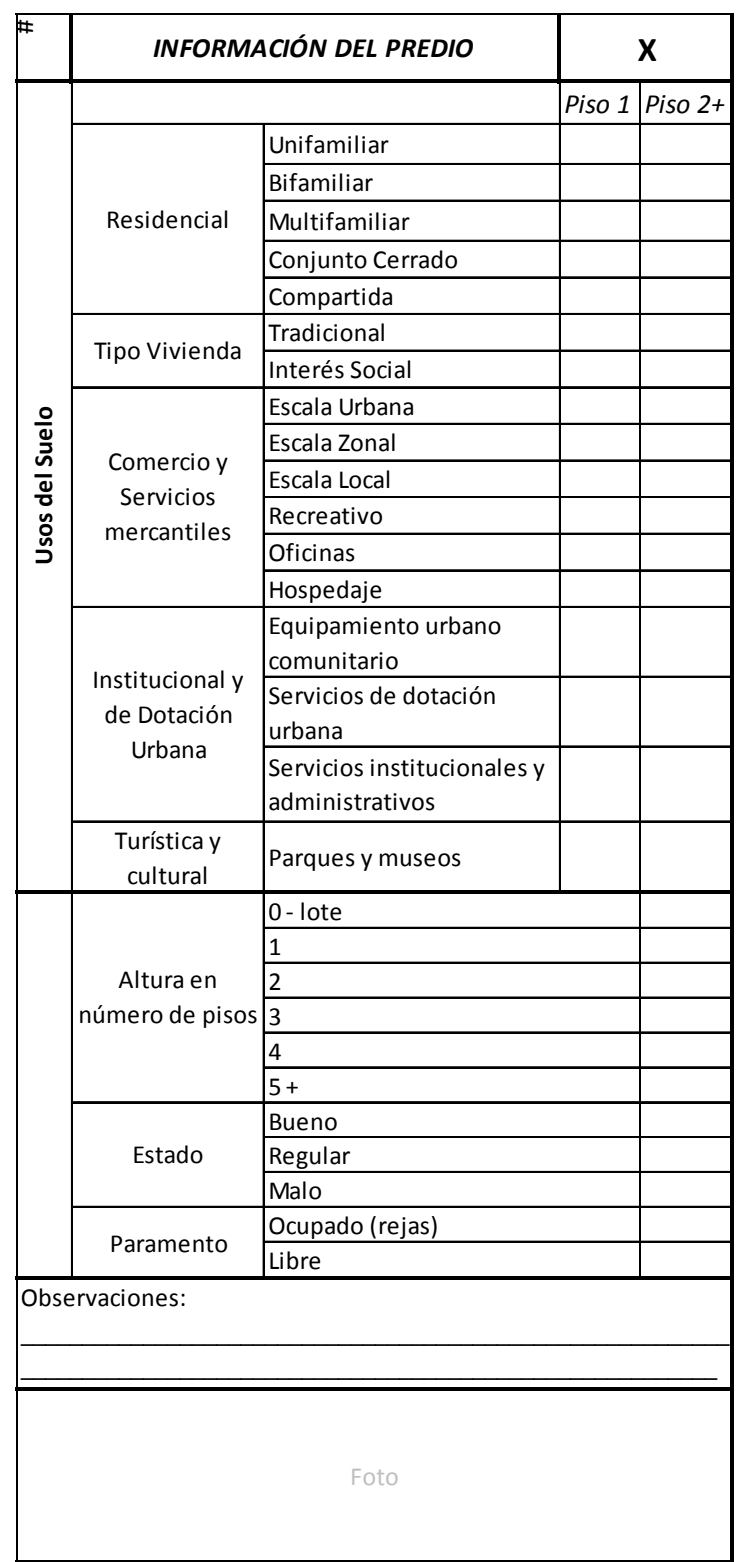

Tabla 4. Matriz de escala predio

Elaborado por el autor

Para este artículo se presentarán en el siguiente capítulo los resultados de haber probado la matriz de escala manzana en 83 polígonos, obteniendo información de 347 bordes, donde se pone en evidencia las falencias de la ciudad caso de estudio en cuanto a su modelo de movilidad en especial en cuanto a los modos de transporte no motorizados como es el caminar y la bicicleta. Así mismo, se detallará una manzana tipo, donde no solo se da una muestra de las características físicas de esta, sino que también de las dinámicas urbanas de la misma, ya que por medio de aforos de tráfico se muestra el comportamiento de la población en cada uno de sus bordes.

\section{DIAGNÓSTICO TERRITORIAL}

Luego de levantar información en 83 manzanas y 347 bordes de las mismas, se procede a la tabulación que se presenta a continuación, donde a través del análisis, surgen las conclusiones que configuran el diagnóstico territorial, para luego presentar el ejemplo con una manzana tipo. 


\begin{tabular}{|c|c|}
\hline Gráfico 1. Estado de los andenes en Zipaquirá & $\begin{array}{l}\text { Para el caso de los andenes se encontró que } 104 \text { están en } \\
\text { buen estado, } 208 \text { regular y } 59 \text { en malas condiciones; este } \\
\text { dato cualitativo tuvo en cuenta las condiciones físicas como } \\
\text { materiales, homogeneidad, texturas e imperfectos más allá } \\
\text { de las dimensiones del mismo. } \\
\text { El dato es positivo en cuanto a que tan solo un } 16 \% \text { se } \\
\text { encuentra deteriorado, sin embargo los andenes en óptimas } \\
\text { condiciones son el } 28 \% \text {, dejando el mayor porcentaje a } \\
\text { aquellos que si bien no están del todo mal, igual tienen varios } \\
\text { imperfectos. }\end{array}$ \\
\hline $\begin{array}{l}350 \\
300 \\
250 \\
200 \\
150 \\
100 \\
50 \\
\text { Grendedor ambuliante } \\
\text { Gráfico 2. Ocupación de lotomotores } \\
\text { Elaborado por el autor }\end{array}$ & $\begin{array}{l}\text { De los } 347 \text { andenes que se revisaron, se encontró que en } 132 \\
\text { había ocupación indebida por parte de automotores, dato } \\
\text { preocupante ya que se no solo se viola una norma de transito } \\
\text { al parquear vehículos en este tipo de espacio público, sino } \\
\text { que esto interrumpe el paso de los peatones, obligándolos a } \\
\text { utilizar la calzada de los carros para realizar sus } \\
\text { desplazamientos, lo cual entre otras pone en riesgo su } \\
\text { seguridad. } \\
\text { Para el caso de vendedores ambulantes y otros, no son datos } \\
\text { tan representativos. }\end{array}$ \\
\hline Lillas & $\begin{array}{l}\text { El mobiliario de mayor presencia en los andenes son las } \\
\text { luminarias, ya que en } 75 \% \text { se encontraron, sin embargo, pese } \\
\text { a ser un porcentaje alto, este debería cubrir la totalidad ya que } \\
\text { es sinónimo de seguridad en las horas nocturnas para } \\
\text { quienes transitan por allí. } \\
\text { Se encontró en general una marcada ausencia del demás } \\
\text { mobiliario como canecas, sillas y paraderos, ya que estos } \\
\text { están presentes en menos del } 12 \% \text { de los bordes de } \\
\text { manzana estudiados. }\end{array}$ \\
\hline $\begin{array}{l}\text { Gráfico 3. Mobiliario en andenes en Zipaquirá } \\
\text { Elaborado por el autor }\end{array}$ & \\
\hline Luminarix Paraderos & $\begin{array}{l}\text { Tan solo en } 152 \text { andenes se encontró señalización vertical, lo } \\
\text { que denota cierta falencia en cuanto a las normas de tránsito, } \\
\text { ya que se cubre apenas el } 42 \% \text { del polígono tomado como } \\
\text { caso de estudio. } \\
\text { La señalización horizontal presenta un panorama mucho peor, } \\
\text { ya que solo en } 70 \text { costados se encontró presencia de esta, lo } \\
\text { que a su vez afecta la legibilidad territorial en el momento de } \\
\text { efectuar desplazamientos en el modo de transporte que sea. }\end{array}$ \\
\hline $\begin{array}{l}\text { Gráfico 4. Señalización en Zipaquirá } \\
\text { Elaborado por el autor }\end{array}$ & \\
\hline $\begin{array}{l}\text { Gráfico 5. Existencia de Ciclorutas } \\
\text { Elaborado por el autor }\end{array}$ & $\begin{array}{l}\text { Uno de los modos de transporte sostenibles a nivel mundial y } \\
\text { que presenta varias externalidades positivas es la bicicleta, } \\
\text { ya que reduce el costo del desplazamiento de manera } \\
\text { considerable, ayuda a la salud de las personas que la usan y } \\
\text { ambientalmente no tiene mayores afectaciones. } \\
\text { De los } 347 \text { costados de manzana evaluados, únicamente } 12 \\
\text { contaban con ciclo-ruta, lo cual es uno de los des-estímulos } \\
\text { más fuertes para un alto porcentaje de la población que usa } \\
\text { este medio de transporte y una evidencia de las falencias que } \\
\text { no solo están en los instrumentos de planeación de la ciudad, }\end{array}$ \\
\hline
\end{tabular}




\begin{tabular}{|c|c|}
\hline & sino también en la realidad física de ésta. \\
\hline Senáforos & $\begin{array}{l}\text { La seguridad vial se ve afectada en parte por la falta de pasos } \\
\text { en intersecciones, que requieren los peatones para efectuar } \\
\text { sus recorridos diarios. Únicamente el } 12 \% \text { de los costados } \\
\text { revisados, contaba en la calle con cebras, el } 6 \% \text { tenía } \\
\text { semáforos y el } 3 \% \text { puentes peatonales (siendo estos últimos } \\
\text { la solución menos adecuada para cruces de peatones). } \\
\text { El resultado muestra un enorme déficit en cuanto a obras que } \\
\text { garanticen la seguridad de los modos de transporte no } \\
\text { motorizados en la ciudad. }\end{array}$ \\
\hline \multicolumn{2}{|l|}{$\begin{array}{l}\text { Gráfico 6. Seguridad Vial en Zipaquirá } \\
\text { Elaborado por el autor }\end{array}$} \\
\hline $\begin{array}{l}\text { - Bueno - Regular - Malo } \\
\text { de las calles en } \\
\text { utor }\end{array}$ & $\begin{array}{l}\text { Las calles en su mayoría se encuentran en regular estado, el } \\
53 \% \text { presenta vías asfaltadas pero con un nivel medio de } \\
\text { deterioro ya sea por huecos, fisuras o acabados no } \\
\text { adecuados. } \\
\text { El } 40 \% \text { de estas infraestructuras se encuentra en buen } \\
\text { estado y solo un } 7 \% \text { está mal. } \\
\text { Los porcentajes que reflejan la calidad de las calles son } \\
\text { similares con los de los andenes, es decir que en general las } \\
\text { condiciones de calles y andenes en cuanto a su estado son } \\
\text { parejas. }\end{array}$ \\
\hline $\begin{array}{l}\text { Gráfico 8. Zonas permitidas y no permitidas c c probitido parquex Prohibido parquear } \\
\text { parqueo en Zipaquirá } \\
\text { Elaborado por el autor }\end{array}$ & $\begin{array}{l}\text { El } 60 \% \text { de las vías permiten el parqueo por parte de los } \\
\text { automotores y el } 40 \% \text { lo prohíbe. } \\
\text { Lo anterior evidencia que una gran cantidad de espacio } \\
\text { público como son las vías, se le está destinando a ser } \\
\text { ocupado por parte de los vehículos. } \\
\text { Si a los anterior se suma el dato de las calles y andenes que } \\
\text { están siendo ocupados por los modos de transporte } \\
\text { motorizados, se encuentra que estos están atentando } \\
\text { físicamente contra los no motorizados ya que ocupan un área } \\
\text { mucho mayor en las diferentes infraestructuras. }\end{array}$ \\
\hline ráfico 9. Vehículos estacionados & $\begin{array}{l}\text { De los } 347 \text { costados estudiados, se encontró que en } 244 \text { de } \\
\text { ellos había vehículos estacionados. Cruzando este dato con la } \\
\text { anterior gráfica, se encuentra que gran parte de estos estaban } \\
\text { en lugares donde es prohibido parquear. En } 169 \text { costados } \\
\text { fueron encontradas motos, siendo estas las que ocupan el } \\
\text { segundo puesto en cuanto a los modos motorizados que más } \\
\text { se parquean en las calles. } \\
\text { El impacto del transporte de carga y del público, ya sean } \\
\text { buses o taxis parece ser mínimo, ya que cada uno de estos } \\
\text { hacía presencia máximo en un } 21 \% \text { de las calles que hicieron }\end{array}$ \\
\hline ido $p$ & \\
\hline
\end{tabular}

El polígono estudiado presenta múltiples problemáticas en cuanto a sus características físicas y a la forma como es utilizado por la población, siendo algunas de las más importantes como que el promedio del ancho del andén pareciera escaso con solo 2.05 metros, mientras que el ancho promedio de la calle arroja 6.35 metros, con una primacía de los 2 carriles; adicionalmente, el diagnóstico arroja una serie de conclusiones y recomendaciones, las cuales son plateadas como reflexiones a la manera como se trazan y operan los modelos de movilidad de las ciudades intermedias en Colombia. 
Por medio del trabajo de campo, se recopilo información sobre una manzana en concreto, debido a las características inherentes a ella se le puede catalogar como una manzana tipo, que permite entender las tendencias en cuanto al funcionamiento del área urbana del municipio, de esta forma se pueden apreciar las características del diagnóstico anteriormente expuesto.

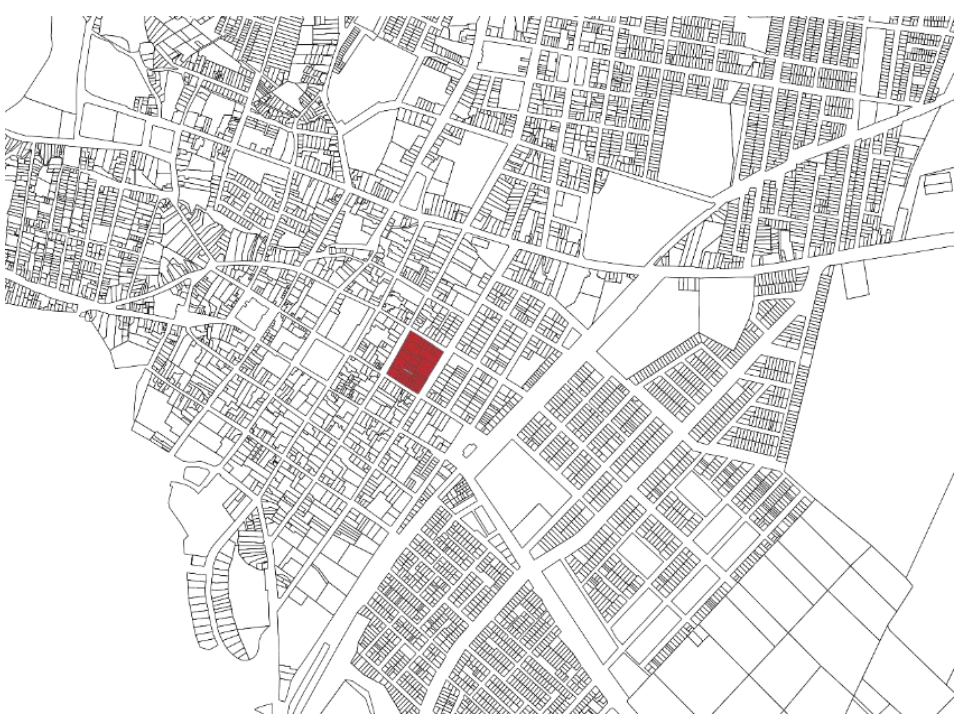

Figura 14: Ubicación de la manzana.

(Complementado de Concejo Municipal de Zipaquirá, 2003)

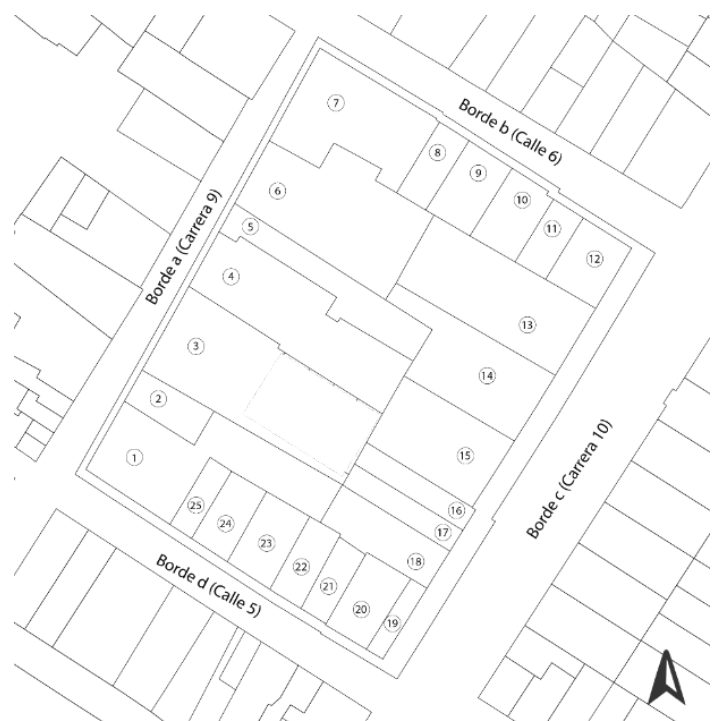

Figura 15: Definición de bordes y numeración de predios. (Complementado de Concejo Municipal de Zipaquirá, 2003)

De igual manera que se hizo con todos los 83 polígonos, se definieron cada uno de los bordes (borde a, b, c, d) y se numeraron los predios, para poder realizar el levantamiento de información implementando la metodología propuesta para el presente estudio.
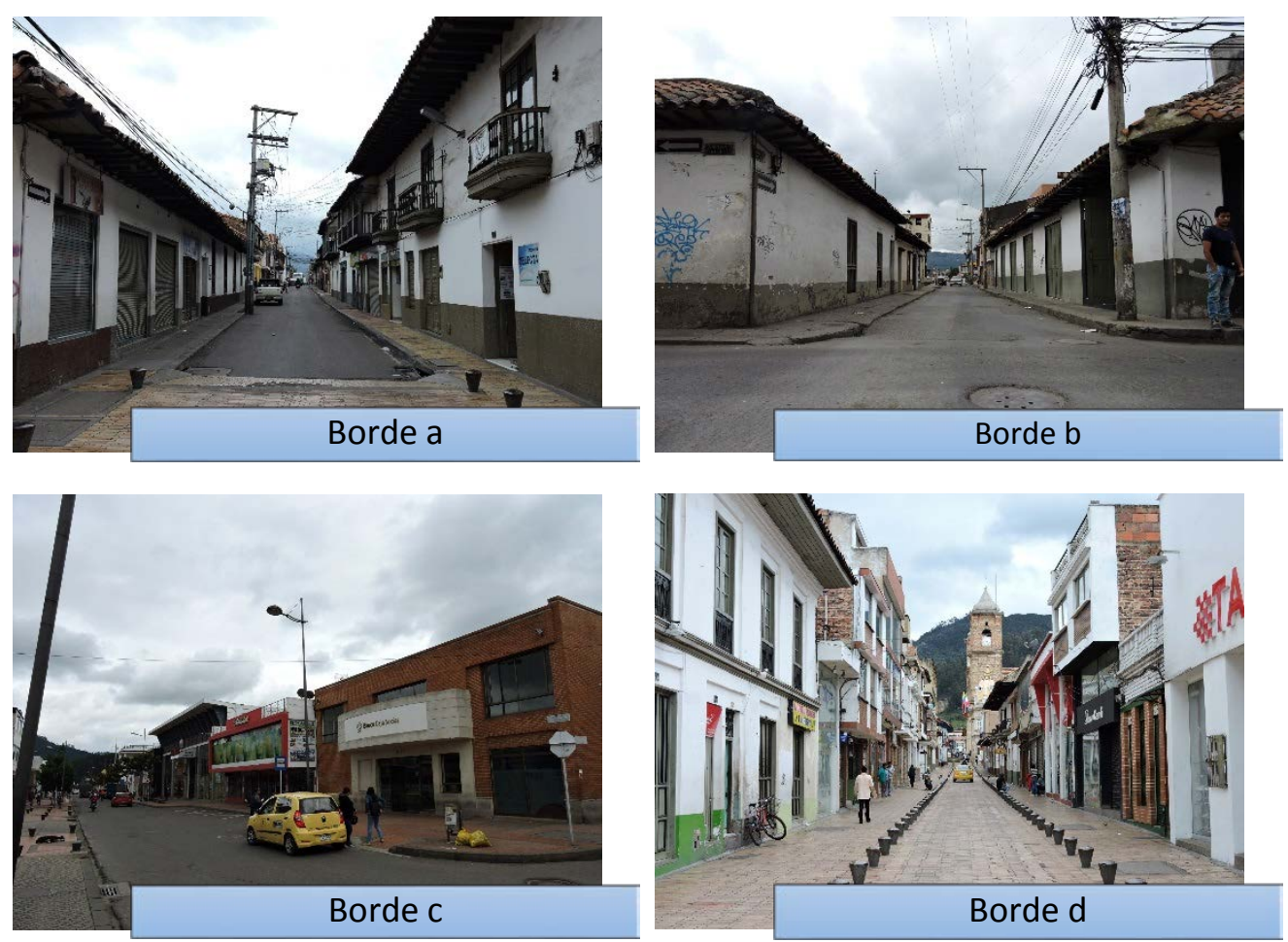

Imagen 4. Fotografías de la manzana tipo (Archivos del autor, 2017) 
El levantamiento en 3D, permite entender aspectos básicos del diagnóstico urbano como son las alturas de los diferentes predios que conforman la manzana y su contexto, los usos predominantes y la relación con el andén y la calzada.

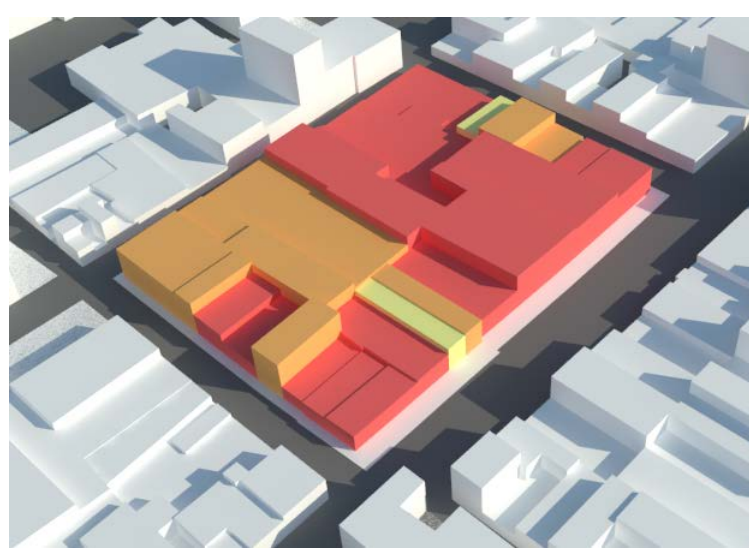

USOS DEL SUELO

Uso comercial

Uso mixto (comercio primer nivel, residencia niveles superiores)

Uso residencial.

Figura 16. 3D de la manzana tipo

(Elaborado por el autor, 2017)

La matriz de escala manzana, permitió identificar características específicas de cada uno de los 83 polígonos que se trabajaron, en la figura 17 se muestra la manera como se utilizó esta herramienta para cada uno de los bordes; los resultados obtenidos demostraban entre otras las grandes diferencias entre los costados que podía tener una misma manzana, como en la tipo, en la que el borde "a" tiene un andén promedio de 1.4 metros de ancho, mientras que el del borde "c" es de 4.6.

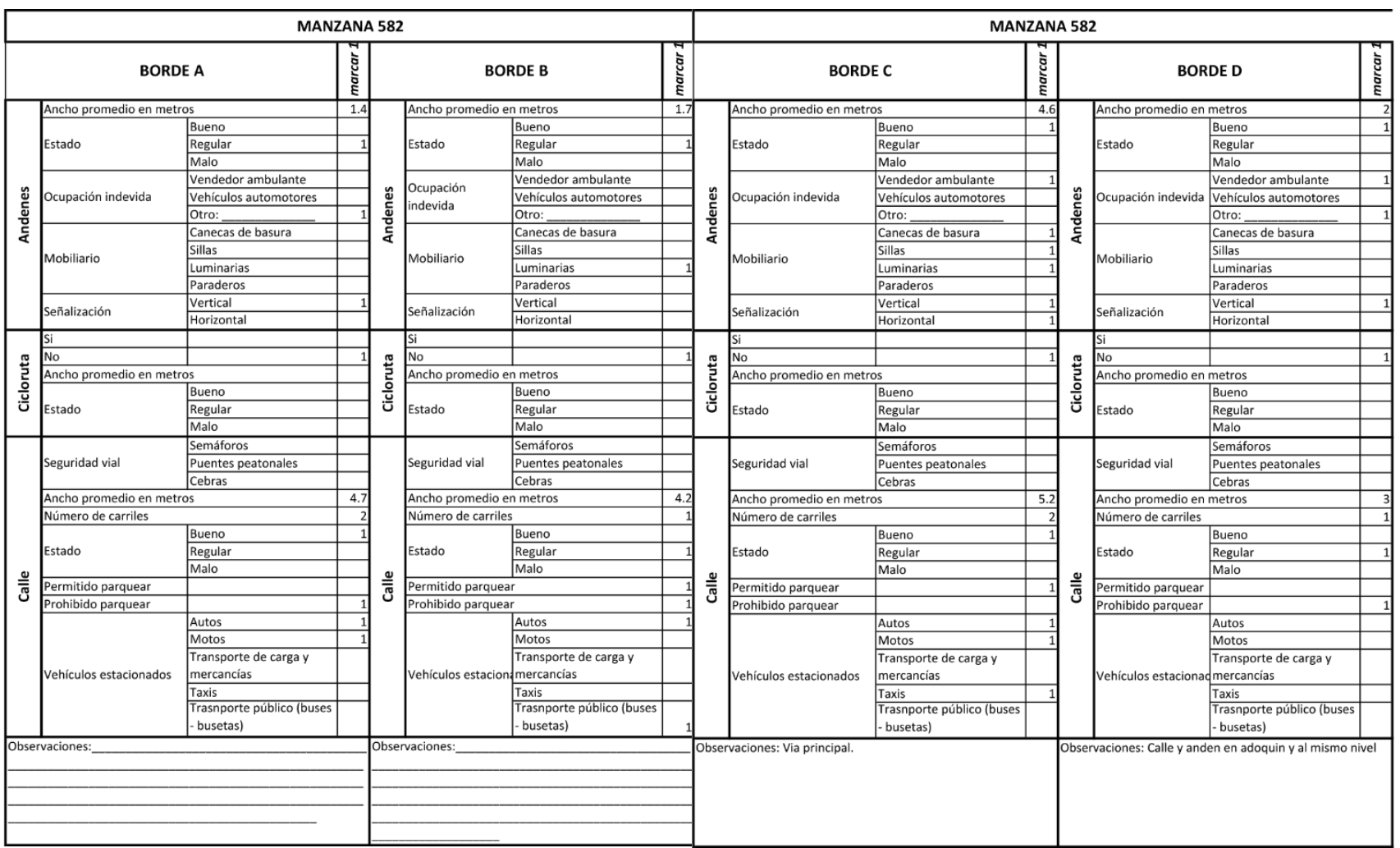

Figura 17. Matriz de la manzana tipo

(Elaborado por el autor, 2017) 
Finalmente, y con base en las características físicas de la manzana, se procede a realizar 2 aforos de tráfico por cada uno de los costados, encontrando la presencia del peatón como el modo predominante en general, seguido por el automotor privado, así mismo la circulación de transporte público en los bordes a, b y c.

Los diferentes datos obtenidos con estas mediciones, dan cuenta de la necesidad de entender no sólo las infraestructuras, sino también la manera como estas son utilizadas para los desplazamientos de la población.

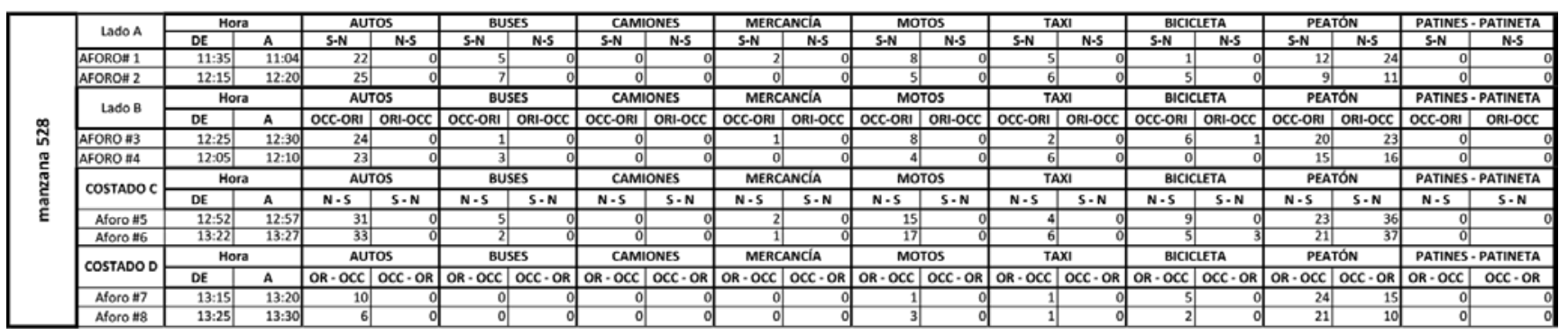

Figura 18. Aforos de tráfico

(Elaborado por el autor, 2017)

\section{CONCLUSIONES Y RECOMENDACIONES}

La validación de la metodología planteada en el caso de estudio, da pie para que esta pueda ser utilizada en otras ciudades intermedias que tengan algunas características similares, ya que si bien los instrumentos de planeación varían en su contenido, el deber ser de la movilidad urbana sostenible sigue siendo el mismo.

El estudio pone en evidencia varios vacíos conceptuales en cuanto a la manera como se está abordando el tema de la movilidad en los instrumentos de planeación del municipio, y gracias al soporte que brinda el marco teórico, la investigación demuestra que la visión de tales instrumentos es más de transporte ya que prioriza en todo momento las infraestructuras viales y los modos motorizados.

Con el levantamiento de información se confirmó que las falencias no sólo se encuentran en los instrumentos de ordenamiento territorial que tiene la ciudad, sino que la realidad es aún más crítica en varios aspectos, como la diferencia porcentual de espacio público que se da a los diferentes modos de transporte, siendo los no motorizados los cuales la ciudad relega y le brinda las peores condiciones.

Según los datos encontrados en terreno, la calidad de las infraestructuras no parece ser una mayor problemática, como si lo puede ser la ocupación indebida de los automotores en los andenes y calles, ya que además de tener estos un porcentaje mucho más elevado en cuanto al área que se les destina, les restan espacio a los peatones.

El uso de la bicicleta como medio de transporte sostenible, se ve opacado por la ausencia casi total de infraestructuras destinadas para este vehículo no motorizado.

Parte del diagnóstico permitió confirmar que la metodología planteada desde las matrices que se diseñaron para el levantamiento de información en terreno se consideran bastante adecuadas, puesto que permitieron tener datos no solo acertados por ser de fuente primaria, sino además con bastante nivel de detalle, lo anterior permite plantear soluciones de igual manera mucho más acertadas que las encontradas en los instrumentos de ordenamiento territorial que suelen ser bastante generales y contradictorias en algunos casos.

Los aforos de tráfico se consideran un complemento acertado para la metodología planteada en el presente artículo, puesto que refleja una realidad dinámica y variable, que permitirá tomar decisiones más adecuadas a las verdaderas problemáticas presentes en las ciudades intermedias colombianas. 


\section{BIBLIOGRAFÍA}

Appleyard, Donald; Gerson, Sue; Lintell, Mark (1981). Livable Streets, University of California. Berkeley. Bazant, Jan (2009). Hacia un desarrollo urbano sustentable, ed. Limusa, México. Benévolo, Leonardo (1999). Historia de la Arquitectura Moderna $8^{a}$ Edición, Ed. Gustavo Gilli, SA. Barcelona. Ceccalli, P., Gabrielli, B., Rozzi, R. (1968). Las Incógnitas del Tráfico Urbano, ed. Gustavo Gilli, s.a. Barcelona. Concejo Municipal de Zipaquirá (2003). Acuerdo 08 del 2003 P.O.T. de Zipaquirá, 29 de agosto del año. Concejo municipal de Zipaquirá (2000). Acuerdo 12 del 2000 P.O.T. de Zipaquirá, 30 de junio del año. Duarte, Eduardo (2009). Una Visión de Transporte Urbano Sostenible en Colombia, Universidad Nacional de Colombia, Facultad de Ingeniería, Bogotá.

Herce, Manuel (2009). Sobre la Movilidad en la Ciudad, ed. Reverté, Barcelona.

Moller R., Beltrán D., Jiménez F. (2009). Transporte Urbano Sostenible y Calidad de Vida para los Municipios de Colombia, programa editorial, Universidad del Valle. Cali 2009.

Montezuma, Ricardo (2010). Movilidad y Ciudad del Siglo XXI, ed. Universidad del Rosario, Bogotá.

Montezuma, Ricardo (1999). Transformación Urbana y Movilidad, Contribución al Debate en América Latina. Septiembre.

Moreno, Milton (2013). "La Movilidad Urbana en Ciudades Intermedias Colombianas. Un Estudio de Caso", Papeles de Coyuntura, n 36, p. $49-58$.

Moreno, Milton (2013). Transporte y Movilidad en el Ordenamiento Territorial de Zipaquirá -Entre la Realidad y la Necesidad-. Tesis de Maestría, Pontificia Universidad Javeriana. Bogotá.

Universidad Nacional de Colombia (2009). Plan de Movilidad Municipio de Zipaquirá, Facultad de Artes, CEA. Bogotá, Noviembre.

Universidad Nacional de Colombia (2011). Segundo Encuentro Iberoamericano de Movilidad Sostenible. Europa y América Latina, Una Mirada al Futuro, Facultad de Economía. Bogotá, Abril.

\section{Referencias electrónicas}

Alcaldía Mayor de Bogotá (2012). Recuperado de http://www.movilidadbogota.gov.co

Alcaldía Municipal de Zipaquirá (2013). Recuperado de http://www.zipaquira-cundinamarca.gov.co

Asociación Iberoamericana para la Movilidad Urbana Sostenible. (2008 - 2013). Recuperado de www.asimus.es

Cycling Embassy of Denmark (2012). Recuperado de www.cycling-embassy.org

Fondo de Prevención Vial (2012). Recuperado de http://www.fonprevial.org.co

International Association of Public Transport (2012). www.uitp.org

Observatorio Movilidad Urbana (2011). Recuperado de www.omu.caf.com

Transport \& Environment (2012). Recuperado de www.transportenvironment.org

Universidad Nacional de Colombia (2012). Centro de Investigaciones para el Desarrollo. Recuperado de www.cid.unal.edu.co 